\title{
Differences in Cardiometabolic Risk Profiles Between Chinese and Finnish Older Adults with Glucose Impairment and Central Obesity
}

Shenglong Le

Shanghai Jiao Tong University

Yinan Zhang

Shanghai 6th Peoples Hospital Affiliated to Shanghai Jiaotong University

Ari Voutilainen

University of Eastern Finland - Kuopio Campus: Ita-Suomen yliopisto - Kuopion kampus

Xiao Tan

Uppsala University

Jari Laukkanen

University of Eastern Finland - Kuopio Campus: Ita-Suomen yliopisto - Kuopion kampus

Congrong Wang

Shanghai Fourth People's Hospital Affiliated to Tongji University

Sulin Cheng ( $\nabla$ shulin.cheng@jyu.fi )

Shanghai Jiao Tong University

Original investigation

Keywords: Type 2 diabetes mellitus, Chinese, Finnish, Ethnicity, Central obesity, Cardiovascular disease risk

Posted Date: October 21st, 2021

DOI: https://doi.org/10.21203/rs.3.rs-983209/v1

License: (c) (i) This work is licensed under a Creative Commons Attribution 4.0 International License. Read Full License

Version of Record: A version of this preprint was published at Journal of Endocrinological Investigation on March 24th, 2022. See the published version at https://doi.org/10.1007/s40618-022-01777-8. 


\section{Abstract \\ Background}

Obesity and ethnicity play important roles in cardiovascular complications in patients with T2DM. This study aimed to compare cardiometabolic risk profiles between Chinese and Finnish older adults with prediabetes or type 2 diabetes mellitus (T2DM) and central obesity.

\section{Methods}

Study subjects were 60-74 years old and originated from two population samples. The Finnish subjects came from the Kuopio Ischemic Heart Disease (KIHD) study $(n=1089)$, and the Chinese subjects came from the Shanghai High-risk Diabetic Screen (SHiDS) study $(n=818)$. The KIHD and SHiDS studies used similar questionnaires to determine participants' baseline characteristics regarding the history of medication use and diseases and lifestyle factors. All study subjects participated in glucose tolerance tests and anthropometry assessments, including waist circumference measurements.

\section{Results}

Among study subjects with prediabetes and central obesity $(n=298)$, fasting glucose, 2-h glucose, fasting insulin, insulin resistance, and triglyceride (TG) levels were significantly higher while the low-density lipoprotein cholesterol (LDL) and LDL to high-density lipoprotein cholesterol $(H D L)$ ratio were lower in Chinese individuals than Finnish individuals ( $p$ $<0.0001-0.003)$. Among subjects with T2DM and central obesity $(n=251)$, Chinese subjects had significantly less proportions of antihypertensive, glycaemic control medication, and statin users as well as lower level of physical activity $(p<0.0001$ for all), while higher blood pressure $(p=0.002$ for systolic blood pressure and $p<0.0001$ for diastolic blood pressure), TG levels $(p<0.05)$ and HDL $(p=0.002)$ than the Finnish counterparts. There were no differences in $\beta$-cell function (HOMA- $\beta$ ) between Chinese and Finnish both in prediabetes and T2DM.

\section{Conclusions}

Our results indicated that Chinese and Finnish older adults with prediabetes and T2DM had similar $\beta$-cell function. However, Chinese individuals with prediabetes are prone to lipid metabolism dysfunction and insulin resistance. Strategies for preventing prediabetes from developing into diabetes in Chinese individuals should be focused on interventions such as exercise to increase insulin sensitivity and prevent insulin resistance. For Finnish individuals with prediabetes, more attention should be given to weight control.

\section{Introduction}

Type 2 diabetes mellitus (T2DM) is the most common metabolic disease, with an increasing prevalence worldwide [1, 2]. According to the 2019 International Diabetes Federation report, the estimated total number of adults with diabetes is 463.0 million worldwide, and among them, more than 90\% have T2DM [1]. Of note, the highest estimated prevalence of diabetes is in people older than 65, with an estimated number of individuals with diabetes of 135.6 million in 2019, and this number is expected to increase dramatically to 276.2 million by 2045 [1]. Cardiovascular diseases (CVDs) are a major cause of death and disability in patients with T2DM [3]. More than 50\% of all patients with T2DM die of CVDs [4]. In elderly individuals with T2DM, a higher absolute risk of CVDs combined with geriatric conditions leads to a high 
mortality rate and increased hospital admission and institutionalization, which comes with inevitable costs to public health and economic challenges [5].

Ethnicity is an important factor that needs to be considered for T2DM and diabetes-related complications. For some ethnic groups, there is a greater predisposition for developing T2DM and diabetes-related complications [4, 6-10]. Compared to their European counterparts, East Asian patients have a greater tendency to develop T2DM at a younger age due to $\beta$ cell dysfunction and insulin resistance $[11,12]$. On the other hand, compared to Asian individuals, European individuals with diabetes are at higher risk of complications such as myocardial infarction, coronary artery disease, lower-extremity gangrene, and large vessel disease but have a lower risk of small vessel disease and diabetic eye and kidney diseases $[4,8,9]$. This predisposition of different ethnic groups to T2DM and its complications are commonly attributed to the complex interaction of genetic and environmental factors $[13,14]$.

Previous studies have shown that cardiovascular biomarkers, low-density lipoprotein (LDL), total cholesterol (TC), cardiac troponin $\mathrm{T}$ and $\mathrm{C}$-reactive protein are systematically higher in Caucasian diabetic patients with acute coronary syndrome than in their Chinese counterparts [15]. Ethnic variations in cardiometabolic risk factors contribute at least in part to the excess CVDs in ethnic minorities. In addition, obesity is a major risk factor for T2DM and is an independent risk factor for CVDs $[1,16]$. There is a positive relationship between obesity and increased prevalence of CVDs in T2DM and prediabetes [16-21]. Using the primary care database of the UK, one study showed that there are important distinctions between ethnic groups, with South Asians showing greater susceptibility to CVDs even at lower body mass index (BMI) levels[22]. Importantly, central obesity is the most important risk factor affecting cardiometabolic risk [23]. However, it is still unclear whether the differences in risk factors between Caucasian and Chinese individuals with prediabetes and T2DM are independent of central obesity.

While obesity and ethnicity play important roles in cardiovascular complications in patients with T2DM, there is almost no any study that has evaluated ethnicity-specific cardiovascular risk profiles of adults with glucose impairment and central obesity at the population level. In the context of increasingly ethnically diverse individuals and ageing in many countries, especially European countries, studies on the relationship between ethnicity, obesity, and cardiovascular complications in elderly individuals with glucose impairment could have an immense impact on public health and the socioeconomic burden of CVDs associated with T2DM [24-26]. Thus, the objective of this study was to examine the cardiometabolic risk profiles of Chinese and Finnish older adults with prediabetes or T2DM and central obesity.

\section{Subjects And Methods}

\section{Study design and participants}

The study subjects were derived from two well-defined population samples. The Finnish subjects came from the Kuopio Ischemic Heart Disease (KIHD) study [27], and the Chinese subjects came from the Shanghai High-risk Diabetic Screen (SHiDS) study [28]. The Finnish KIHD study was a prospective population-based cohort study designed to investigate risk factors for atherosclerotic CVD and other related chronic disease outcomes. The KIHD cohort was employed for the current analysis and initially comprised 1774 invited participants (920 women and 854 men) who were aged 53 to 74 years who participated from March 1998 to February 2001. The Chinese study was conducted at the 6th Hospital affiliated with Shanghai Jiao Tong University. The total sample consisted of 2445 Chinese individuals, with an age range from 30 to 74 . Since we are interested in late adulthood, only those aged $60 \leq$ to $\leq 74$ years were included in this report. Thus, the final sample comprised 1089 Finnish and 818 Chinese individuals.

Similar questionnaires examining history of medication use and diseases; lifestyle, including smoking, drinking and physical activity habits; and education level were used to characterize the background of the participants. The Finnish study was approved by the Ethics Committee of Kuopio University and Kuopio University Hospital, Kuopio, Finland 
(licence number 143/97), and the Chinese study was approved by the Ethics Committee of Shanghai Jiao Tong University 6th Hospital (2018-KY-056 (K)). Written informed consent was obtained from all participants, and all study procedures were conducted according to the Declaration of Helsinki.

\section{Anthropometric and body composition assessment}

Body weight and height were measured with standard methods and used to calculate BMI. Blood pressure was measured with the conventional method (in Finland with a Hawksley random zero sphygmomanometer and in China with an Omron HBP-9020s (Omron Healthcare, Kyoto, Japan)). Waist circumference (WC) and hip circumference were measured by tape. The waist circumference to hip circumference ratio (WHR) was calculated.

\section{Biochemical measurements}

Blood samples were collected in the morning between 7:00 and 9:00 a.m. after overnight fasting at both sites. Serum was extracted by centrifugation and stored immediately at $-80^{\circ} \mathrm{C}$ until analysis. Glucose tolerance tests were performed at both sites after overnight fasting, and samples were taken 30 minutes and 2 hours after the intake of $75 \mathrm{~g}$ glucose for the assessment of serum insulin (chemiluminescent immunoassay) and glucose (automatic biochemistry analyser). The homeostasis model assessment of insulin resistance index (HOMA-IR) was calculated as (fasting insulin concentration $x$ fasting glucose concentration)/22.5, and the $\beta$-cell function index (HOMA- $\beta$ ) was calculated as $(20 \times f$ asting insulin concentration/(fasting glucose concentration -3.5)[29]. The serum lipid [30] and plasma glucose [27] analysis methods used in Finland have been described previously. In China, the plasma glucose analysis method has been described previously [28], and serum TC, high-density lipoprotein (HDL), LDL and triglyceride (TG) were analysed using a Hitachi Automatic Analyzer 7600 (Hitachi High-Technologies, Tokyo, Japan). The inter- and intra-assay CVs were 3.4\% and 2.9\% for TG, $2.0 \%$ and $3.7 \%$ for glucose, and $11 \%$ and $3.4 \%$ for insulin, respectively.

\section{Criteria for prediabetes, T2DM and central obesity}

The criterion for prediabetes was defined according to the American Diabetes Association criteria as a fasting glucose level from $5.6 \mathrm{mmol} / \mathrm{l}$ to $6.9 \mathrm{mmol} / \mathrm{I}$ or an OGTT $2 \mathrm{~h}$ glucose level from $7.0 \mathrm{mmol} / \mathrm{l}$ to $11.0 \mathrm{mmol} / \mathrm{l}$ [31]. The criterion for T2DM was defined as a fasting glucose level $\geq 7.0 \mathrm{mmol} / \mathrm{I}$ or an OGTT $2 \mathrm{~h}$ glucose level $\geq 11.1 \mathrm{mmol} / \mathrm{I}$ [31]. Subjects receiving drug therapy for diabetes were also included in the T2DM group. Central obesity was indicated by waist circumference $\geq 94 \mathrm{~cm}$ for Europid men, $\geq 90 \mathrm{~cm}$ for Chinese men and $\geq 80 \mathrm{~cm}$ for women in both countries [32].

\section{Statistical analysis}

Statistical analyses were performed using IBM SPSS Statistics for Windows, Version 21.0. Descriptive statistics were generated and presented for each ethnic group, including percentages for categorical variables and means and $95 \%$ confidence intervals for continuous variables. The Shapiro-Wilk test was used to check all data for normality. If the data were not normally distributed, a log transformation was used to ensure a normal distribution. Categorical variables were compared between Chinese and Finnish individuals using the chi-square test for independence. Continuous variables were compared between Chinese and Finnish individuals by using Student's t-test in univariate analysis or Mann-Whitney $\mathrm{U}$ tests. Analysis of covariance (ANCOVA) was used to control for confounding factors such as age, sex, BMI and medicine when comparing the variables between the Chinese and Finnish populations. Pearson correlation analysis was performed to evaluate the correlation between central obesity (BMI and waist circumference) and glycaemic and lipid variables. In addition, generalized linear models (GLMs) were used to control for confounding factors such as age, sex, $\mathrm{BMI}$ and medicine when assessing the relationships among BMI, WC and glycaemic and lipid variables.

\section{Results}




\section{Profiles of Chinese and Finnish older adults with glucose impairment and central obesity}

Among the targeted population, $18.3 \%(n=199)$ of the Finnish population had prediabetes, and 7.9\% $(n=85)$ had T2DM, while 30.6\% $(n=250)$ had prediabetes and 31.8\% $(n=260)$ had T2DM in the Chinese population. Since the purpose of this report was to examine the differences in the cardiometabolic risk profiles of Finnish and Chinese older adults with glucose impairment and central obesity, the following results are only related to the comparison of prediabetes and T2DM between Finnish and Chinese individuals with central obesity. However, for the purpose of comparison, we also assessed the differences between subjects without and with central obesity. The results are given in Supplementary

Tables 1 and 2. In Finnish individuals, those patients with central obesity had significantly higher weight, WC, and fasting insulin than those without central obesity in both the prediabetes and T2DM populations, higher HOMA-IR in the prediabetes population and higher TG levels in the T2DM population ( $p<0.05$ to 0.001$)$. The corresponding differences in Chinese subjects were weight, WC, systolic blood pressure (SBP), and fasting insulin in both groups and SBP, HOMA-IR, HOMA- $\beta$ in the prediabetes group, and TC in the T2DM group ( $p<0.05$ to 0.001 ). 
Table 1

General characteristics of Chinese and Finnish older adults with glucose impairment and central obesity

\begin{tabular}{|c|c|c|c|c|c|c|c|c|}
\hline & \multicolumn{4}{|c|}{ Pre-diabetes } & \multicolumn{4}{|c|}{ T2DM } \\
\hline & \multicolumn{2}{|c|}{ Chinese } & \multicolumn{2}{|c|}{ Finnish } & \multicolumn{2}{|c|}{ Chinese } & \multicolumn{2}{|c|}{ Finnish } \\
\hline & $\mathrm{n}$ & $\begin{array}{l}\text { mean }(95 \% \\
\mathrm{Cl})\end{array}$ & $\mathrm{n}$ & $\begin{array}{l}\text { Mean }(95 \% \\
\mathrm{Cl})\end{array}$ & $\mathrm{n}$ & $\begin{array}{l}\text { mean }(95 \% \\
\mathrm{Cl})\end{array}$ & $\mathrm{n}$ & $\begin{array}{l}\text { Mean }(95 \% \\
\mathrm{Cl})\end{array}$ \\
\hline Age, years & 147 & $\begin{array}{l}63.7(63.2 \\
64.1)\end{array}$ & 151 & $\begin{array}{l}67.9(67.2 \\
68.5)^{\star \star}\end{array}$ & 172 & $\begin{array}{l}64.4(63.9 \\
64.9)\end{array}$ & 79 & $\begin{array}{l}67.9(67 \\
68.7)^{\star \star}\end{array}$ \\
\hline Height, cm & 147 & $\begin{array}{l}162(161, \\
163)\end{array}$ & 151 & $\begin{array}{l}165 \text { (164, } \\
167)^{\# \#}\end{array}$ & 172 & $\begin{array}{l}164(162, \\
165)\end{array}$ & 79 & $\begin{array}{l}164(162, \\
167)\end{array}$ \\
\hline Weight, kg & 147 & $\begin{array}{l}67.2(65.4 \\
69.0)\end{array}$ & 151 & $\begin{array}{l}82.0(80.2 \\
83.7) \#\end{array}$ & 172 & $\begin{array}{l}68.5(66.9 \\
70)\end{array}$ & 79 & $\begin{array}{l}80.8 \text { (77.8, } \\
83.8) \# \#\end{array}$ \\
\hline $\mathrm{BMI}, \mathrm{kg} / \mathrm{m}^{2}$ & 147 & $25.5(25,26)$ & 151 & $\begin{array}{l}30.1(29.5 \\
30.6)\end{array}$ & 172 & $\begin{array}{l}25.5(25.1 \\
25.9)\end{array}$ & 79 & $\begin{array}{l}29.8(29 \\
30.6)\end{array}$ \\
\hline $\mathrm{WC}, \mathrm{cm}$ & 147 & $\begin{array}{l}91.5(90.4, \\
92.7)\end{array}$ & 151 & $\begin{array}{l}99.0(97.7 \\
100.5)^{\star \star}\end{array}$ & 172 & $\begin{array}{l}92.9 \\
(91.8,94.1)\end{array}$ & 79 & $\begin{array}{l}100.4 \\
(98.1,102.7) \\
\star \star\end{array}$ \\
\hline WHR & 146 & $\begin{array}{l}0.92(0.91 \\
0.93)\end{array}$ & 151 & $\begin{array}{l}0.94(0.92 \\
0.95)\end{array}$ & 172 & $\begin{array}{l}0.94(0.93 \\
0.95)\end{array}$ & 79 & $\begin{array}{l}0.96(0.94 \\
0.98) \#\end{array}$ \\
\hline SBP, mmHg & 146 & $\begin{array}{l}139(136, \\
142)\end{array}$ & 151 & $\begin{array}{l}141(138, \\
144)\end{array}$ & 170 & $\begin{array}{l}137(135 \\
140)\end{array}$ & 79 & $\begin{array}{l}133(129, \\
137)\end{array}$ \\
\hline $\mathrm{DBP}, \mathrm{mmHg}$ & 146 & $\begin{array}{l}81.6(80.1, \\
83.1)\end{array}$ & 151 & $\begin{array}{l}81.1(79.7 \\
82.6)\end{array}$ & 170 & $\begin{array}{l}82.4(81.0, \\
83.9)\end{array}$ & 79 & $\begin{array}{l}75.8 \text { (73.7, } \\
77.8)\end{array}$ \\
\hline $\begin{array}{l}\text { Education, } 1 / 2 / 3^{\square}, \\
\%^{\dagger}\end{array}$ & 146 & $6.2 / 73.3 / 20.5$ & 151 & $80.8 / 15.2 / 4.0$ & 172 & $5.2 / 61.0 / 33.7$ & 79 & $87.3 / 10.1 / 2.5$ \\
\hline $\begin{array}{l}\text { Gender } \\
\text { (female/male), } \%^{\dagger}\end{array}$ & 147 & $68.7 / 31.3$ & 151 & 51.7/48.3 \#\# & 172 & $66.9 / 33.1$ & 79 & 49.4/50.6 \#\# \\
\hline $\begin{array}{l}\text { Smoking (yes/no), } \\
\%^{+}\end{array}$ & 145 & $4.1 / 95.9$ & 151 & $10.6 / 89.4{ }^{\#}$ & 164 & $10.4 / 89.6$ & 76 & $7.9 / 92.1$ \\
\hline
\end{tabular}

Cl: confidence interval; T2DM: type 2 diabetes; BMI: body mass index; WC: waist circumference WHR: waist-to-hip ratio; SBP: systolic blood pressure; DBP: diastolic blood pressure; NA: not applicable.

$\mathrm{BMI}$ in T2DM was log-transformed for the analysis.

$\triangle$ Education: 1 = primary/below, 2 = high school, 3 = graduate/above.

† Values are number of subjects with proportion (\%).

* $p<0.05$, ** $p<0.01$, comparison of the means between Chinese and Finns by the Mann-Whitney $U$ test.

$\# p<0.05$, \#\# $p<0.01$, comparison of the means between Chinese and Finns by Student's t-test or proportions by chisquare test or rank sum test.

†† $p<0.01$, comparison of the means between Chinese and Finn populations by analysis of covariance (ANCOVA) controlling for age, sex, BMI and anti-hypertension medicine. 


\begin{tabular}{|c|c|c|c|c|c|c|c|c|}
\hline \multirow[b]{2}{*}{$\begin{array}{l}\text { Alcohol drinking } \\
\text { (yes/no), } \%^{\dagger}\end{array}$} & \multicolumn{4}{|c|}{ Pre-diabetes } & \multicolumn{4}{|c|}{ T2DM } \\
\hline & 146 & $17.8 / 82.2$ & 151 & $6.0 / 94.0$ \#\# & 164 & $10.4 / 89.6$ & 77 & $13.0 / 87.0$ \\
\hline $\begin{array}{l}\text { Diabetes of family } \\
\text { (yes/no), } \%^{\dagger}\end{array}$ & 143 & $38.5 / 61.5$ & 151 & $37.7 / 62.3$ & 165 & $51.5 / 48.5$ & 79 & $48.1 / 51.9$ \\
\hline $\begin{array}{l}\text { Use of statins } \\
\text { (yes/no), \% }\end{array}$ & 147 & $1.4 / 98.6$ & 151 & $5.3 / 94.7$ & 172 & $4.1 / 95.9$ & 79 & $13.9 / 86.1^{\# \#}$ \\
\hline $\begin{array}{l}\text { Use of } \\
\text { antihypertensive } \\
\text { medication } \\
\text { (yes/no), } \%^{\dagger}\end{array}$ & 147 & $9.5 / 90.5$ & 151 & $58.9 / 41.1 \#$ & 172 & $30.8 / 69.2$ & 79 & $78.5 / 21.5^{\# \#}$ \\
\hline $\begin{array}{l}\text { Use of antidiabetic } \\
\text { medication } \\
\text { (yes/no), } \%^{\dagger}\end{array}$ & NA & NA & NA & NA & 172 & $1.7 / 98.3$ & 48 & $60.8 / 39.2 \#$ \\
\hline $\begin{array}{l}\text { Physical activity } \\
\text { (yes/no), } \%^{\dagger}\end{array}$ & 146 & $77.4 / 22.6$ & 151 & $98.7 / 1.3 \#$ & 172 & $72.7 / 27.3^{\star \star}$ & 77 & $96.1 / 3.9 \#$ \\
\hline $\begin{array}{l}\text { Frequency, } \\
\text { times/week }\end{array}$ & 113 & $4.6(4.0,5.2)$ & 151 & $\begin{array}{l}6.7(6.0,7.4) \\
\# \#\end{array}$ & 99 & $5.6(4.9,6.3)$ & 73 & $5.4(4.8,6.1)$ \\
\hline $\begin{array}{l}\text { Duration, } \\
\text { hours/week }\end{array}$ & 113 & $4.6(3.8,5.4)$ & 151 & $\begin{array}{l}10.2 \text { (8.7, } \\
11.4)\end{array}$ & 99 & $5.1(4.3,5.9)$ & 73 & $\begin{array}{l}7.8(6.5,9.2) \\
\# \#\end{array}$ \\
\hline $\begin{array}{l}\text { Intensity } \\
\text { (low/medium/high), } \\
\%\end{array}$ & 113 & $53.1 / 46.0 / 0.9$ & 149 & $\begin{array}{l}\text { 6.0/90.6/3.4 } \\
\# \#\end{array}$ & 125 & $82.4 / 17.6 / 0.0$ & 74 & $\begin{array}{l}12.2 / 78.4 / 9.5 \\
\# \#\end{array}$ \\
\hline \multicolumn{9}{|c|}{$\begin{array}{l}\text { Cl: confidence interval; T2DM: type } 2 \text { diabetes; BMl: body mass index; WC: waist circumference WHR: waist-to-hip } \\
\text { ratio; SBP: systolic blood pressure; DBP: diastolic blood pressure; NA: not applicable. }\end{array}$} \\
\hline \multicolumn{9}{|c|}{ BMI in T2DM was log-transformed for the analysis. } \\
\hline \multicolumn{9}{|c|}{$\triangle$ Education: 1 = primary $/$ below, 2 = high school, 3 = graduate/above.} \\
\hline \multicolumn{9}{|c|}{ † Values are number of subjects with proportion (\%). } \\
\hline \multicolumn{9}{|c|}{$\star p<0.05$, ** $p<0.01$, comparison of the means between Chinese and Finns by the Mann-Whitney U test. } \\
\hline \multicolumn{9}{|c|}{$\begin{array}{l}\# p<0.05, \# \# p<0.01 \text {, comparison of the means between Chinese and Finns by Student's t-test or proportions by chi- } \\
\text { square test or rank sum test. }\end{array}$} \\
\hline $\begin{array}{l}\dagger+p<0.01 \text {, comparis } \\
\text { controlling for age, se }\end{array}$ & $\begin{array}{l}\text { of th } \\
\text { BMI }\end{array}$ & $\begin{array}{l}\text { means betwee } \\
\text { d anti-hyperten }\end{array}$ & hin & $\begin{array}{l}\text { and Finn por } \\
\text { cine. }\end{array}$ & ions & analysis of & & e (ANCOVA) \\
\hline
\end{tabular}

The general characteristics of the subjects with prediabetes and T2DM and central obesity are shown in Table 1. Finnish individuals were older ( $p<0.0001$ for all) and heavier $(p<0.0001$ for all) and had a larger BMI $(p<0.0001$ for all) than Chinese individuals in both the prediabetes and T2DM groups. Among T2DM patients, the Chinese population had a smaller WHR $(p=0.046)$ than the Finnish population. The Chinese population also had lower participation in physical activity ( $p<0.0001$ for all) than the Finnish population in both the prediabetes and T2DM groups. The proportion of alcohol drinking was significantly higher in Chinese individuals with prediabetes than in their Finnish counterparts ( $p=$ 0.002), while the proportion of smoking was higher in Finnish individuals $(p=0.033)$. Among prediabetes patients, the proportion of individuals using antihypertensive medication was significantly lower among Chinese individuals than among Finnish individuals $(p<0.0001)$. The proportion of individuals using antihypertensive and antidiabetic 
medication as well as statins was significantly lower in Chinese individuals than in Finnish individuals $(p<0.0001$ for all) with T2DM. Among T2DM patients, Chinese patients had higher blood pressure ( $p=0.04$ for SBP and $p<0.0001$ for diastolic blood pressure (DBP)). After controlling for age, sex, BMI, and the use of antihypertensive medication, the significance remained the same.

Walking was the most common type of leisure time physical activity (LTPA) for both Finnish and Chinese individuals. In addition to walking, hunting, fishing, and gymnastics were common LTPAs among Finnish individuals, while less than $10 \%$ of Chinese engaged in Taiji, dancing, and jogging (Figure 1). Among prediabetes patients, Chinese individuals reported participating in LTPA less frequently $(p=0.003)$, for a shorter duration $(p<0.0001)$ and at a lower intensity $(p<$ 0.0001) than Finnish individuals. In T2DM patients, Chinese patients had a similar frequency of LTPA to Finnish patients but a shorter duration $(p=0.002)$ and lower intensity $(p<0.0001)$.

\section{Comparison of glycaemic variables between Chinese and Finnish older adults with glucose impairment and central obesity}

Among prediabetes patients, the Chinese population had higher fasting glucose and $2 \mathrm{~h}$ glucose (see Table 2). After controlling for age, sex and BMI, Chinese individuals had higher fasting insulin (adjusted mean difference of the logtransformed $=0.167,95 \% \mathrm{Cl}: 0.102,0.232, \mathrm{df}=1, \mathrm{~F}=25.643, \mathrm{p}<0.0001$, partial $\eta^{2}=0.082$ ) and HOMA-IR (adjusted mean difference of the log-transformed $=0.204,95 \% \mathrm{Cl}: 0.136,0.271, \mathrm{df}=1, \mathrm{~F}=35.088, \mathrm{p}<0.0001$, partial $\left.\eta^{2}=0.109\right)$. After additional confounding factors, such as antidiabetic medication, SBP, education, physical activity, smoking and alcohol consumption, were added to the model, the significance remained the same. In T2DM patients, after controlling for age, sex, BMI and use of antidiabetic medication, 2-h glucose was significantly higher in Chinese individuals than in Finnish individuals $(p<0.05)$. However, after adding SBP, education, LTPA, smoking and alcohol drinking to the model, this significance disappeared. 
Table 2

Glycaemic variables of Chinese and Finnish older adults with glucose impairment and central obesity

\begin{tabular}{|c|c|c|c|c|c|c|c|c|}
\hline & \multicolumn{4}{|c|}{ Pre-diabetes } & \multicolumn{4}{|c|}{ T2DM } \\
\hline & \multicolumn{2}{|c|}{ Chinese } & \multicolumn{2}{|c|}{ Finnish } & \multicolumn{2}{|c|}{ Chinese } & \multicolumn{2}{|c|}{ Finnish } \\
\hline & $\mathrm{n}$ & mean $(95 \% \mathrm{Cl})$ & $\mathrm{n}$ & Mean $(95 \% \mathrm{Cl})$ & $\mathrm{n}$ & $\begin{array}{l}\text { mean }(95 \% \\
\mathrm{Cl})\end{array}$ & $\mathrm{n}$ & Mean $(95 \% \mathrm{Cl})$ \\
\hline $\begin{array}{l}\mathrm{Glu}_{0} \\
\mathrm{mmol} / \mathrm{I}\end{array}$ & 147 & $\begin{array}{l}5.85(5.75, \\
5.95)\end{array}$ & 151 & $5.42(5.32,5.53)^{\star *}$ & 172 & $\begin{array}{l}6.97(6.79 \\
7.14)\end{array}$ & 79 & $\begin{array}{l}7.94(7.35, \\
8.53)\end{array}$ \\
\hline $\begin{array}{l}\mathrm{Glu}_{2 \mathrm{~h}} \\
\mathrm{mmol} / \mathrm{l}\end{array}$ & 147 & $\begin{array}{l}8.29(8.01, \\
8.58)\end{array}$ & 151 & $7.96(7.73,8.2)$ * & 172 & $\begin{array}{l}14.8(14.3 \\
15.2)\end{array}$ & 57 & $\begin{array}{l}14.5(13.1,16) \\
\#\end{array}$ \\
\hline $\mathrm{Ins}_{0}, \mathrm{mmol} / \mathrm{I}$ & 143 & $\begin{array}{l}12.9(11.7, \\
14.1)\end{array}$ & 151 & $\begin{array}{l}11.2(10.4,12.1) \\
\# \#++\end{array}$ & 171 & $\begin{array}{l}13.5(12.4 \\
14.5)\end{array}$ & 79 & $16.9(12.7,21)$ \\
\hline HOMA-IR & 143 & $\begin{array}{l}3.33(3.02, \\
3.64)\end{array}$ & 150 & $\begin{array}{l}2.73(2.49,2.97) \\
\# \#++\end{array}$ & 170 & $\begin{array}{l}4.13(3.79 \\
4.46)\end{array}$ & 79 & $6.45(4.21,8.7)$ \\
\hline HOMA- $\beta$ & 137 & $111(99,123)$ & 150 & $125(115,135)$ & 170 & $\begin{array}{l}85.6(77.5 \\
93.7)\end{array}$ & 79 & $\begin{array}{l}93.4(76.5 \\
110.3)\end{array}$ \\
\hline \multicolumn{9}{|c|}{$\begin{array}{l}\text { T2DM: type } 2 \text { diabetes; Cl: confidence interval; } \mathrm{Glu}_{0} \text { : fasting glucose level; } \mathrm{Glu}_{2 h} \text { : } 2-\mathrm{h} \text { glucose level; Ins }{ }_{0} \text { : fasting } \\
\text { insulin level; HOMA-IR: homeostasis model assessment of insulin resistance; HOMA- } \beta \text { : homeostasis model } \\
\text { assessment of } \beta \text {-cell function index. }\end{array}$} \\
\hline \multicolumn{9}{|c|}{$\begin{array}{l}\text { Ins } s_{0}, \mathrm{HOMA}-\mathrm{IR} \text { and HOMA-B in prediabetes and } \mathrm{Glu}_{0}, \mathrm{Glu}_{2 h} \text {, Ins } \mathrm{I}_{0} \text {, and HOMA-IR in T2DM were log-transformed for the } \\
\text { analysis. }\end{array}$} \\
\hline \multicolumn{9}{|c|}{$\begin{array}{l}{ }^{*} \mathrm{p}<0.05,{ }^{*} \mathrm{p}<0.01 \text {, comparison of the means between Chinese and Finnish populations by the Mann-Whitney } U \\
\text { test. }\end{array}$} \\
\hline \multicolumn{9}{|c|}{$\begin{array}{l}\# p<0.05, \# \# p<0.01 \text {, comparison of the means between Chinese and Finnish populations by analysis of } \\
\text { covariance }(A N C O V A) \text { controlling for age, sex, BMI and anti-diabetes medicine. }\end{array}$} \\
\hline
\end{tabular}

\section{Comparison of lipid profiles between Chinese and Finnish older adults with glucose impairment and central obesity}

In prediabetes patients, after controlling for age, sex, BMI, and the use of statins, the Chinese population had higher TG (adjusted mean difference $=0.475,95 \% \mathrm{Cl}: 0.205,0.746, \mathrm{df}=1, \mathrm{~F}=11.955, \mathrm{p}=0.001$ ) but lower LDL (adjusted mean difference $=-0.522,95 \% \mathrm{Cl}:-0.864,-0.180, \mathrm{df}=1, \mathrm{~F}=9.029, \mathrm{p}=0.003$ ) levels and LDL/HDL ratios (adjusted mean difference $=-0.759,95 \% \mathrm{Cl}:-1.130,-0.389, \mathrm{df}=1, \mathrm{~F}=16.271, \mathrm{p}<0.000$, Figure 2). In T2DM patients, only TG levels were higher in Chinese patients (adjusted mean difference $=0.412,95 \% \mathrm{Cl}: 0.055,0.769, \mathrm{df}=1, \mathrm{~F}=5.193, \mathrm{p}=0.024$ ). No other differences between the Chinese and Finnish populations with T2DM and central obesity were observed.

\section{Correlations between central obesity and glycaemic and lipid profiles}

We assessed the correlations between central obesity and glycaemic and lipid profiles. The results are given in Supplementary Table 3. Significant associations were found between BMI/WC and insulin/HOMA-IR in both the Finnish 
and Chinese populations (all $p<0.05-0.001$ ). In addition, in Finnish individuals, WC was significantly correlated with fasting glucose, TGs and HDL, while in Chinese individuals; WC was only positively correlated with HOMA- $\beta$ in prediabetes patients. TGs were positively correlated with BMI and WC, and HDL was negatively correlated with WC in Finnish individuals, while in Chinese individuals, only BMI was positively correlated with HOMA- $\beta$ in T2DM patients. Controlling for all the confounding factors (age, sex, drinking, smoking, medications and LTPA), the significant associations between BMI/WC and fasting glucose, insulin, HOMA-IR and HOMA- $\beta$ in Finnish and Chinese prediabetes patients and between BMI/WC and TGs, fasting insulin, and HOMA-IR in Finnish T2DM patients remained, but they disappeared between WC and HDL in Finnish T2DM patients. Interestingly, the associations between HOMA- $\beta$ and $\mathrm{BMI} / \mathrm{WC}$ in Finnish individuals and between HOMA- $\beta$ and WC in Chinese T2DM individuals appeared significant.

\section{Discussion}

In this cross-sectional study, we compared the cardiometabolic profiles of Finnish and Chinese older adults with prediabetes or T2DM and central obesity, and we observed several differences between these two ethnic groups. Specifically, among older adult participants with prediabetes and central obesity, fasting glucose, insulin, HOMA-IR, and TG were significantly higher, while LDL and LDL/HDL ratio were lower, in Chinese individuals than in Finnish individuals. Even after controlling for all confounding factors, significance remained. However, among older adult participants with T2DM and central obesity, only TGs were significantly higher in Chinese individuals than in Finnish individuals. Interestingly, the associations between BMI/WC and HOMA-IR/HOMA- $\beta$ were similar in the prediabetes and T2DM populations and between ethnic groups.

Most of the early reports on the differences in risk factors for prediabetes and T2DM between ethnicities did not take central obesity into account. In this study, we found that the differences between subjects with and without central obesity were mainly in weight, WC, insulin level and insulin resistance in both ethnic groups and in both the prediabetes and T2DM populations. This result indicated that in addition to central obesity, insulin resistance is one of the first signs of glucose impairment in the development of T2DM regardless of ethnicity. On the other hand, prediabetes and T2DM in Chinese individuals may be due more to dysfunction of the cardiovascular system, as indicated by blood pressure, than in Finnish individuals. One meta-analysis showed that the prevalence of overall CVDs, stroke and coronary artery disease was higher in Western Pacific (including China) than in European T2DM populations [4].

When only subjects with central obesity and prediabetes were included, the differences between Finnish and Chinese subjects were related not only to insulin resistance but also to the levels of glucose, TGs and LDL and the LDL/HLD ratio. Central obesity rather than obesity defined by BMI has been associated with various detrimental metabolic consequences, such as dysglycaemia and dyslipidaemia, all of which cause cardiovascular mortality [33]. A consensus statement pointed out that [33] "the lack of inclusion of waist circumference in global obesity surveillance might inadequately characterize the health risk associated with the global obesity prevalence, as it seems that the prevalence of abdominal obesity is increasing"; therefore, it was recommended that measurement of waist circumference should be included in obesity surveillance studies. In this study, we included measures of WC and WHR. We found that in prediabetes patients, there were significant differences in both BMI and WC but not in WHR between Finnish and Chinese individuals. Higher BMI and WC were significantly correlated with higher levels of fasting insulin and HOMA-IR/HOMA- $\beta$ in both ethnic groups. These associations were independent of age, sex, drinking, smoking, medications and physical activity.

However, there are ethnic differences regarding lipid metabolism between Finnish and Chinese individuals with prediabetes or T2DM. The risk of unhealthy lipid profiles, such as high TGs, may lead to cardiovascular diseases [34], dementia caused by Alzheimer's disease [35], and frailty [36], thus predisposing patients to an increased risk of mortality and lower quality of life. It is possible that differences in body composition, particularly visceral fat accumulation, cause

Page $10 / 17$ 
high TGs in Asian populations [37]. A previous study showed that compared with European cohorts, Chinese cohorts had a relatively greater amount of abdominal adipose tissue, and this difference was more pronounced in visceral fat [38]. Greater visceral fat mass was also associated with both higher TG levels and higher insulin resistance levels in normal weight but metabolically obese Japanese adults [39]. However, in this report, we did not have body composition data; thus, it cannot be confirmed that the high TG levels in Chinese older adults are associated with high body fat content. On the other hand, we noticed that the Chinese population in both the prediabetes and T2DM groups spent much less time performing LTPAs and did so at a lower intensity than their Finnish counterparts. Low levels of PA or a sedentary lifestyle may lead to high TG levels and insulin resistance [40-42]. Therefore, promotion of physical activity in the Chinese population with central obesity and prediabetes or T2DM is a necessary strategy for prevention.

Existing studies have mainly compared the differences between different ethnic groups within the same country, and fewer comparisons of the differences between ethnic groups on different continents have been reported [10,43,44]. Increased mobility due to globalization, particularly during the last two decades, has brought new challenges for health care systems in different countries. Immigrants frequently take their culture and lifestyle with them to their new place of settlement [45]. There are differences in predisposition to developing T2DM and diabetes-related complications [4, 6-10]. However, there are no ethnically specific criteria or strategic considerations for T2DM prevention, diagnosis and treatment in clinical practice in any country. Our results provide information on risk factor differences from countries on different continents. However, this study has some limitations. The study has a cross-sectional design. The Chinese T2DM patients were mostly newly diagnosed, which may have influenced the outcomes. No body composition measurements were taken, no dietary information was collected, and differences in dietary intake may have impacted the results, since glycaemic responses following ingestion of glucose and several rice varieties are appreciably greater in Chinese individuals than in European individuals [46]. Nevertheless, this study may encourage clinicians to take into account the differences between ethnic groups in the future.

\section{Conclusions}

In conclusion, by comparing the cardiometabolic profiles of Finnish and Chinese prediabetes and T2DM populations, we found that both Finnish and Chinese older adults had similar $\beta$-cell function. However, Chinese individuals with prediabetes are prone to lipid metabolism dysfunction and insulin resistance. Strategies for preventing prediabetes from developing into diabetes in Chinese individuals should be focused on interventions such as exercise to increase insulin sensitivity and prevent insulin resistance. For Finnish individuals with prediabetes, more attention should be given to weight control.

\section{Abbreviations}

T2DM: type 2 diabetes mellitus; KIHD: Kuopio Ischemic Heart Disease; SHiDS: Shanghai High-risk Diabetic Screen; TG: triglyceride; HOMA-IR: homeostasis model assessment of insulin resistance index; LDL: low density lipoprotein cholesterol; HDL: high density lipoprotein cholesterol; CVDs: cardiovascular diseases; TC: total cholesterol; BMI: body mass index; WC: waist circumference; WHR: waist circumference to hip circumference; HOMA- $\beta$ : homeostasis model assessment of $\beta$-cell function index; ANCOVA: analysis of covariance; GLM: generalized linear model; SBP: systolic blood pressure; DBP: diastolic blood pressure; LTPA: leisure time physical activity; Cl: confidence interval; NA: not applicable; Glu0: fasting glucose level; Glu2h: 2-h glucose level; Ins0: fasting insulin level.

\section{Declarations}

\section{Ethics approval and consent to participate}


The Finnish study was approved by the Ethics Committee of Kuopio University and Kuopio University Hospital, Kuopio, Finland (licence number 143/97), and the Chinese study was approved by the Ethics Committee of Shanghai Jiao Tong University 6th Hospital (2018-KY-056 (K)). Written informed consent was obtained from all participants, and all study procedures were conducted according to the Declaration of Helsinki.

\section{Consent for publication}

Not applicable.

\section{Availability of data and materials}

The data that support the findings of this study are available from the corresponding author upon reasonable request.

\section{Competing interests}

All authors declare that they have no competing interests.

\section{Funding}

This work was partly supported by the National Natural Science Foundation of China (NSFC 81770883, 82070913), the Research Start-up Fund from Shanghai Fourth People's Hospital (sykyqd02101), and the Shanghai Science and Technology Development Fund (20ZR1446000).

\section{Authors' contributions}

SL conceptualized and designed the study, conducted the data analysis, interpreted the data and drafted the initial version of this manuscript. SC conceptualized and designed the study, supervised the analysis, interpreted the data and reviewed and revised the manuscript. XT conceptualized the study and revised the manuscript. YZ, AV, JL and CW interpreted the data and revised the manuscript. All authors read and approved the final manuscript.

\section{Acknowledgements}

The authors thank all participants and investigators in the Kuopio Ischemic Heart Disease (KIHD) study and the Chinese subjects from the Shanghai High-risk Diabetic Screen (SHiDS) study.

\section{References}

1. International Diabetes Federation. IDF Diabetes Atlas 2019. 2019. https://diabetesatlas.org/en/resources/ IDF Diabetes Atlas 2019. Accessed 8 Mar 2021.

2. World Health Organization. Global report on diabetes. 2016.

https://www.who.int/publications/i/item/9789241565257. Accessed 8 Mar 2021.

3. International Diabetes Federation. Diabetes and cardiovascular disease. Brussels: International Diabetes Federation; 2016.

4. Einarson TR, Acs A, Ludwig C. Prevalence of cardiovascular disease in type 2 diabetes: a systematic literature review of scientific evidence from across the world in 2007-2017. Cardiovasc Diabetol. 2018;17(1):83.

5. Sinclair A, Morley JE, Rodriguez-Mañas L, Paolisso G, Bayer T, Zeyfang A, et al. Diabetes mellitus in older people: position statement on behalf of the International Association of Gerontology and Geriatrics (IAGG), the European Diabetes Working Party for Older People (EDWPOP), and the International Task Force of Experts in Diabetes. J Am Med Dir Assoc. 2012;13(6):497-502. 
6. Paul SK, Owusu Adjah ES, Samanta M, Patel K, Bellary S, Hanif W, et al. Comparison of body mass index at diagnosis of diabetes in a multi-ethnic population: A case-control study with matched non-diabetic controls. Diabetes Obes Metab. 2017;19(7):1014-23.

7. Hsu WC, Araneta MR, Kanaya AM, Chiang JL, Fujimoto W. BMI cut points to identify at-risk Asian Americans for type 2 diabetes screening. Diabetes Care. 2015;38(1):150-8.

8. Ma RC, Chan JC. Type 2 diabetes in East Asians: similarities and differences with populations in Europe and the United States. Ann N Y Acad Sci. 2013;1281(1):64-91.

9. Zheng Y, Ley SH, Hu FB. Global aetiology and epidemiology of type 2 diabetes mellitus and its complications. Nat Rev Endocrinol.. 2018;14(2):88-98.

10. Meeks KAC, Freitas-Da-Silva D, Adeyemo A, Beune EJAJ, Modesti PA, Stronks K, et al. Disparities in type 2 diabetes prevalence among ethnic minority groups resident in Europe: a systematic review and meta-analysis. Intern Emerg Med. 2016;11(3):327-40.

11. Chan JCN, Malik V, Jia W, Kadowaki T, Yajnik CS, Yoon K-H, et al. Diabetes in Asia: epidemiology, risk factors, and pathophysiology. JAMA. 2009;301(20):2129-40.

12. Kato N. Ethnic diversity in type 2 diabetes genetics between East Asians and Europeans. J Diabetes Investig. 2012;3(4):349-51.

13. Carulli L, Rondinella S, Lombardini S, Canedi I, Loria P, Carulli N. Review article: diabetes, genetics and ethnicity. Aliment Pharmacol Ther. 2005;22 Suppl 2:16-9.

14. Murea M, Ma L, Freedman BI. Genetic and environmental factors associated with type 2 diabetes and diabetic vascular complications. Rev Diabet Stud. 2012;9(1):6-22.

15. Buljubasic N, Zhao W, Cheng J, Li H, Oemrawsingh R, Akkerhuis M, et al. Comparison of temporal changes in established cardiovascular biomarkers after acute coronary syndrome between Caucasian and Chinese patients with diabetes mellitus. Biomarkers. 2020;25(4):341-8.

16. Katsiki N, Anagnostis P, Kotsa K, Goulis DG, Mikhailidis DP. Obesity, metabolic syndrome and the risk of microvascular complications in patients with diabetes mellitus. Curr Pharm Des. 2019;25(18):2051-9.

17. Boonman-de Winter LJ, Rutten FH, Cramer MJ, Landman MJ, Liem AH, Rutten GE, et al. High prevalence of previously unknown heart failure and left ventricular dysfunction in patients with type 2 diabetes. Diabetologia. 2012;55(8):2154-62.

18. Bhatti GK, Bhadada SK, Vijayvergiya R, Mastana SS, Bhatti JS. Metabolic syndrome and risk of major coronary events among the urban diabetic patients: North Indian Diabetes and Cardiovascular Disease Study-NIDCVD-2. J Diabetes Complications. 2016;30(1):72-8.

19. Wentworth JM, Fourlanos S, Colman PG. Body mass index correlates with ischemic heart disease and albuminuria in long-standing type 2 diabetes. Diabetes Res Clin Pract. 2012;97(1):57-62.

20. Glogner S, Rosengren A, Olsson M, Gudbjörnsdottir S, Svensson AM, Lind M. The association between BMI and hospitalization for heart failure in 83,021 persons with Type 2 diabetes: a population-based study from the Swedish National Diabetes Registry. Diabet Med. 2014;31(5):586-94.

21. Laitinen T, Lindström J, Eriksson J, llanne-Parikka P, Aunola S, Keinänen-Kiukaanniemi S, et al. Cardiovascular autonomic dysfunction is associated with central obesity in persons with impaired glucose tolerance. Diabet Med. 2011;28(6):699-704.

22. Owusu Adjah ES, Bellary S, Hanif W, Patel K, Khunti K, Paul SK. Prevalence and incidence of complications at diagnosis of T2DM and during follow-up by BMI and ethnicity: a matched case-control analysis. Cardiovasc Diabetol. 2018;17(1):70. 
23. Kelishadi R, Mirmoghtadaee P, Najafi H, Keikha M. Systematic review on the association of abdominal obesity in children and adolescents with cardio-metabolic risk factors. J Res Med Sci. 2015;20(3):294-307.

24. Gholap N, Davies M, Patel K, Sattar N, Khunti K. Type 2 diabetes and cardiovascular disease in South Asians. Prim Care Diabetes. 2011;5(1):45-56.

25. Bodicoat DH, Gray LJ, Henson J, Webb D, Guru A, Misra A, et al. Body mass index and waist circumference cut-points in multi-ethnic populations from the UK and India: the ADDITION-Leicester, Jaipur heart watch and New Delhi crosssectional studies. PloS one. 2014;9(3):e90813.

26. Fernando E, Razak F, Lear SA, Anand SS. Cardiovascular Disease in South Asian Migrants. Can J Cardiol. 2015;31(9):1139-50.

27. Kunutsor SK, Laukkanen JA. Serum zinc concentrations and incident hypertension: new findings from a populationbased cohort study. J Hypertens. 2016;34.

28. Gao F, Zhang Y, Ge S, Lu H, Chen R, Fang P, et al. Coffee consumption is positively related to insulin secretion in the Shanghai High-Risk Diabetic Screen (SHiDS) Study. Nutr Metab. 2018;15(1):84.

29. Matthews DR, Hosker JP, Rudenski AS, Naylor BA, Treacher DF, Turner RC. Homeostasis model assessment: insulin resistance and $\beta$-cell function from fasting plasma glucose and insulin concentrations in man. Diabetologia. 1985;28(7):412-9.

30. Salonen JT, Salonen R, Seppanen K, Rauramaa R, Tuomilehto J. HDL, HDL2, and HDL3 subfractions, and the risk of acute myocardial infarction. A prospective population study in eastern Finnish men. Circulation. 1991;84(1):129-39.

31. Association AD. 2. Classification and Diagnosis of Diabetes: Standards of Medical Care in Diabetes-2019. Diabetes Care. 2019;42 Suppl 1:13-28.

32. Alberti KG, Zimmet P, Shaw J. Metabolic syndrome--a new world-wide definition. A Consensus Statement from the International Diabetes Federation. Diabet Med. 2006;23(5):469-80.

33. Ross R, Neeland IJ, Yamashita S, Shai I, Seidell J, Magni P, et al. Waist circumference as a vital sign in clinical practice: a Consensus Statement from the IAS and ICCR Working Group on Visceral Obesity. Nat Rev Endocrinol. 2020;16(3):177-89.

34. Nordestgaard BG, Varbo A. Triglycerides and cardiovascular disease. Lancet. 2014;384(9943):626-35.

35. Raffaitin C, Gin H, Empana JP, Helmer C, Berr C, Tzourio C, et al. Metabolic syndrome and risk for incident Alzheimer's disease or vascular dementia: the Three-City Study. Diabetes care. 2009;32(1):169-74.

36. Ramsay SE, Arianayagam DS, Whincup PH, Lennon LT, Cryer J, Papacosta AO, et al. Cardiovascular risk profile and frailty in a population-based study of older British men. Heart. 2015;101(8):616-22.

37. Hwang YC, Fujimoto WY, Hayashi T, Kahn SE, Leonetti DL, Boyko EJ. Increased Visceral Adipose Tissue Is an Independent Predictor for Future Development of Atherogenic Dyslipidemia. J Clin Endocrinol Metab. 2016;101(2):678-85.

38. Lear SA, Humphries KH, Kohli S, Chockalingam A, Frohlich JJ, Birmingham CL. Visceral adipose tissue accumulation differs according to ethnic background: results of the Multicultural Community Health Assessment Trial (M-CHAT). Am J Clin Nutr. 2007;86(2):353-9.

39. Katsuki A, Sumida Y, Urakawa H, Gabazza EC, Murashima S, Maruyama N, et al. Increased visceral fat and serum levels of triglyceride are associated with insulin resistance in Japanese metabolically obese, normal weight subjects with normal glucose tolerance. Diabetes care. 2003;26(8):2341-4.

40. Bailey DP, Charman SJ, Ploetz T, Savory LA, Kerr CJ. Associations between prolonged sedentary time and breaks in sedentary time with cardiometabolic risk in 10-14-year-old children: The HAPPY study. J Sports Sci.

2017;35(22):2164-71.

Page $14 / 17$ 
41. Fernández-García JC, Muñoz-Garach A, Martínez-González MÁ, Salas-Salvado J, Corella D, Hernáez Á, et al. Association Between Lifestyle and Hypertriglyceridemic Waist Phenotype in the PREDIMED-Plus Study. Obesity. 2020;28(3):537-43.

42. Dos Santos ESM, Máximo RO, de Andrade FB. Differences in the prevalence of prediabetes, undiagnosed diabetes and diagnosed diabetes and associated factors in cohorts of Brazilian and English older adults. Public Health Nutr. 2021;24(13):4187-4194.

43. Zafarmand MH, Tajik P, Spijker R, Agyemang C. Gene-environment Interaction on the Risk of Type 2 Diabetes Among Ethnic Minority Populations Living in Europe and North America: A Systematic Review. Curr Diabetes Rev. 2020;16(5):457-70.

44. Dal Canto E, Farukh B, Faconti L. Why are there ethnic differences in cardio-metabolic risk factors and cardiovascular diseases? JRSM Cardiovasc Dis. 2018;7:2048004018818923.

45. Popovic-Lipovac A, Strasser B. A review on changes in food habits among immigrant women and implications for health. J Immigr Minor Health. 2015;17(2):582-90.

46. Kataoka M, Venn BJ, Williams SM, Te Morenga LA, Heemels IM, Mann JI. Glycaemic responses to glucose and rice in people of Chinese and European ethnicity. Diabet Med. 2013;30(3):e101-7.

\section{Figures}
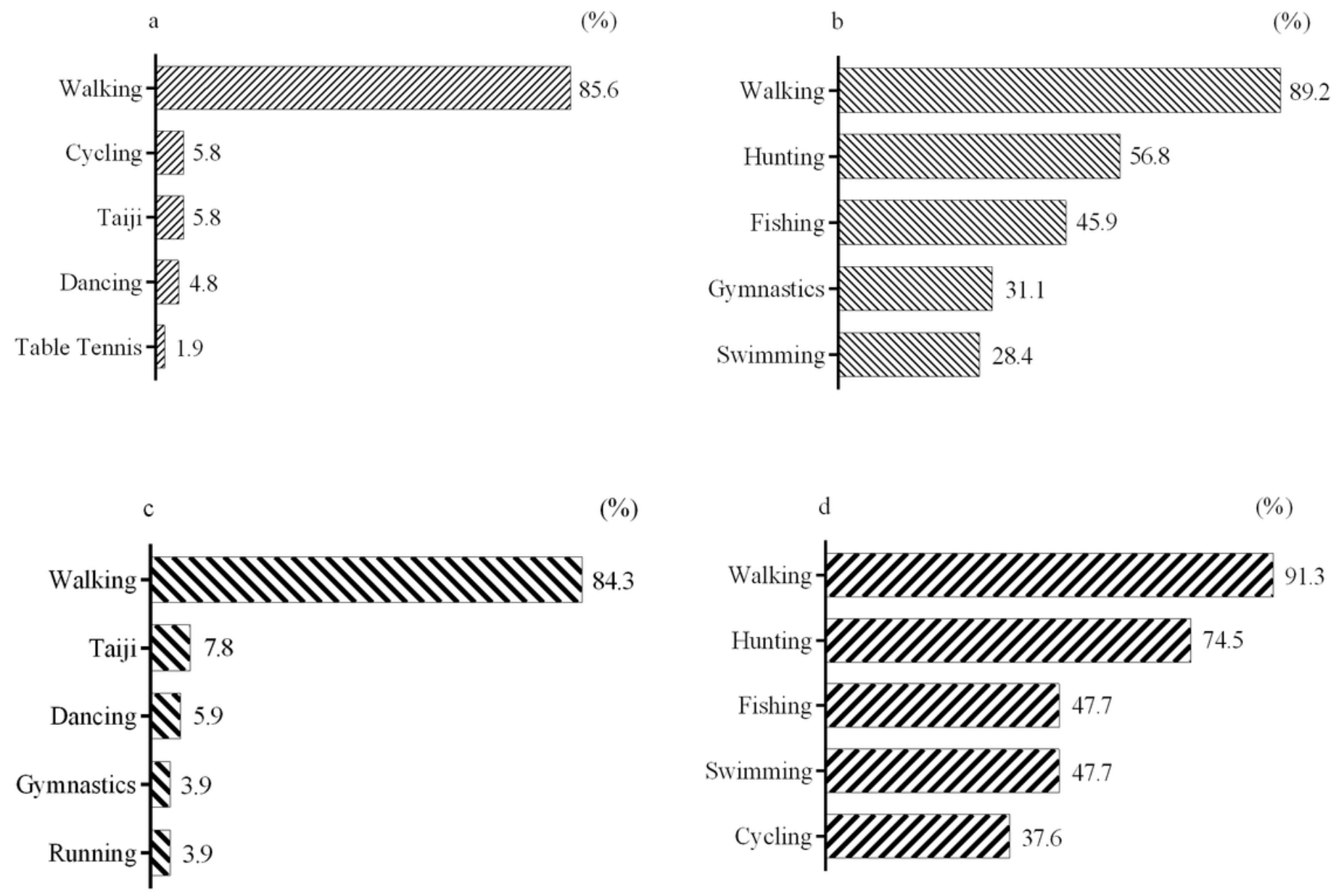

Figure 1 
Top 5 LTPAs participated by Chinese and Finnish with glucose impairment and central obesity. a: Chinese prediabetes patients; b: Finnish prediabetes patients; c: Chinese T2DM patients; d: Finnish T2DM patients. LTPA: leisure time physical activities.
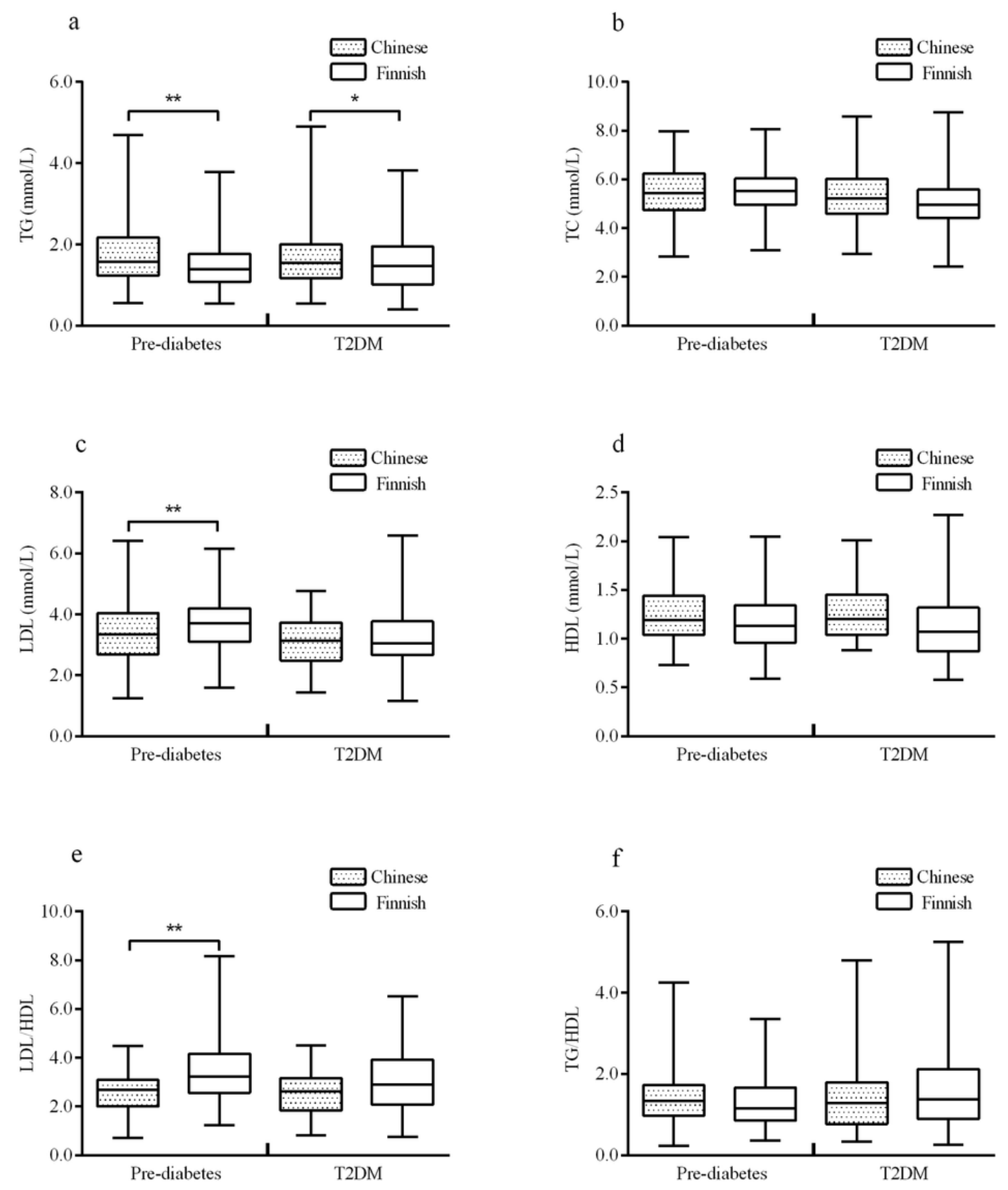

\section{Figure 2}

Comparison of lipid profiles between Chinese and Finnish populations with glucose impairment and central obesity. TG: triglyceride; TC: total cholesterol; LDL: low-density lipoprotein cholesterol; HDL: high-density lipoprotein cholesterol. The Mann-Whitney $\mathrm{U}$ test was used to assess the difference in HDL in between Chinese and Finnish T2DM populations. Analysis of covariance (ANCOVA) was used to assess the differences in the remaining variables adjusting for age, sex, BMI and use of statins. ${ }^{*} p<0.05 ; * \star p<0.01$.

\section{Supplementary Files}


This is a list of supplementary files associated with this preprint. Click to download.

- supplementary.docx 